\title{
Neck Pain and Disability: Eye Drop Installation Technique As a Causative Factor
}

\author{
Erkam KÖMÜRCÜ, ${ }^{1}$ Selçuk KARA, ${ }^{2}$ Umut Hatay GÖLGE, ${ }^{1}$ Burak KAYMAZ, ${ }^{1}$ Sedat ARIKAN, ${ }^{2}$ \\ Baran GENCER, ${ }^{2}$ Ferdi GÖKSEL, ${ }^{1}$ Ferhat GÖKMEN ${ }^{3}$ \\ ${ }^{1}$ Department of Orthopaedics and Traumatology, Medical Faculty of Onsekiz Mart University, Çanakkale, Turkey \\ ${ }^{2}$ Department of Ophthalmology, Medical Faculty of Onsekiz Mart University, Çanakkale, Turkey \\ ${ }^{3}$ Department of Physical Therapy and Rehabilitation, Medical Faculty of Onsekiz Mart University, Çanakkale, Turkey
}

\begin{abstract}
Objectives: This study aims to investigate a possible relationship between long standing eye drop usage and neck pain and to determine the optimal neck position while instilling the eye drop.

Patients and methods: Sixty-seven patients who admitted to the ophthalmology outpatient clinic with the diagnosis of glaucoma and using eye drops for at least one year were included in the study as group $1(n=31)$. The ages of the patients were between 18 to 80 years. A control group (group $2, n=36$ ) was selected from age-matched individuals who did not use eye drops. The neck disability index form and a study form which included demographic data and the method of eye drop usage of patients were filled.

Results: The mean age of the patients were $55.7 \pm 11.5$ and $53.5 \pm 17.1$ years for group 1 and group 2 , respectively. There was no significant difference in the age and sex between the groups $(p=0.526$ and $p=0.396$, respectively). Compared to the controls, the chronic eye drop usage and its application method produced significant difference in neck disability index $(p<0.001)$. Also, there was a positive correlation between neck disability index and number of eye drop usage per a day and period of eye drop usage ( $p=0.003$ and $p=0.004$, respectively).

Conclusion: Neck posture which is not placed in hyperextension position during administration of eye drop may reduce postural neck malpositionrelated neck disability. Patients who are on eye drop for a long time should be informed about postural disorders and instructed to correct the administration of eye drop technique to avoid neck pain.

Keywords: Eye drop; glaucoma; neck disability index; neck pain.
\end{abstract}

Neck pain, one of the most important health problems of today, is not a straightforward neurophysiological condition. It is a multifactorial disease with various risk factors including physical, psychological and the individual, which contribute to development of pain. ${ }^{1}$ These risk factors are closely related to specific occupational groups. ${ }^{2}$ Cervical postural disorders may cause increased extensor muscle activity with detrimental strain of neck muscles. It has also been suggested that there might be a potential relationship between forward head posture and neck pain..$^{3-5}$

Glaucoma is one of the causes of blindness and reduction of intraocular pressure is the mainstay of the treatment to prevent blindness. ${ }^{6}$ Although laser and surgical treatment options are available for this purpose, topical medical treatment is the most frequent and the most preferred method. ${ }^{7-9}$ Patients use one or several eye drops regularly every day. ${ }^{10}$ Majority of glaucoma patients instill eye drops by keeping their heads in the hyperextension position. Repetitive unsuitable postures of the cervical vertebrae may lead to cervical problems. ${ }^{1}$

We hypothesized that repetitive hyperextension posture for eye drop instillation causes detrimental strain in the neck muscles, and subsequently chronic neck pain. The aim of this study was to evaluate whether there is a relationship between long-term eye drop usage and neck pain and also 
to determine the optimal position of the neck while instilling the eye drop.

\section{PATIENTS AND METHODS}

Approval for this study was obtained from the institutional ethics committee and was conducted in accordance with the declaration of Helsinki. The verbal and signed written informed consent of this study was collected from all participants.

Sixty-seven patients (aged between 18-80 years) with the diagnosis of glaucoma and using eye drops for at least one year and were able to give consent were included in the study as group 1 ( $n=31$ ). Patients were asked to complete the form prepared to determine the neck position while using the eye drops, and the Turkish version of Neck Disability Index (NDI). ${ }^{11,12}$ The latter included 10 sections: pain intensity; personal care; lifting; reading; headaches; concentration; work; driving; sleeping; and recreation. There were six questions in each section. Item scores ranged from 0 (no disability) to 5 (total disability). The control group (group 2, n=36) was selected from individuals (between 18-80 years of age) who presented at the ophthalmology clinic and did not use any eye drops.

Excluded from the study were patients with a history of cervical problems like vertebral fractures, disc herniation, traumatic injuries, regional tumors, previous neck surgery, psychiatric patients, pregnancy, and those who could not read the NDI form. To determine the method of use of the eye drops, patients were asked to describe the positions in which they used the eye drop; 1- Instilling the eye drop him/herself in the sitting position (with cervical hyperextension), 2- Instilling the eye drop him/ herself in the supine position (without cervical hyperextension), 3- Another person instills the eye drop in the sitting position (with cervical hyperextension), 4- Another person instills the eye drop in the supine position (without cervical hyperextension). Responses of patients about instillation of eye drop methods were obtained with the help of pictures.

\section{Statistical analysis}

Statistical analysis was performed by using the Statistical Package for Social Sciences for Windows version 19.0 (SPSS Inc., Chicago, IL, USA) software program. Descriptive statistics were used for defining socio-demographic and basic clinical variables. The Chi-square test was used to compare categorical variables. Normality of continuous data was determined by the Kolmogorov-Smirnov test. When normality of the distribution of variables was acceptable, the Student t-test, or in other cases the MannWhitney $U$ test were used to analyze differences between two independent sample groups and the Kruskal Wallis tests were used to analyze three independent samples. The Bonferroni adjusted Kruskal Wallis test was also used to exclude the type I error between the groups and a $p$ value less of than $0.017 \quad(p<0.017)$ was considered statistically significant. Correlations between the explanatory variables were calculated by using Spearman's correlation test and differences were accepted as significant at $p<0.05$ for all tests (two tailed).

\section{RESULTS}

The mean ages of patients who were included in the study were $55.7 \pm 11.5$ and $53.5 \pm 17.1$ years respectively for group 1 and group 2 . There was no significant difference between the groups in terms of age and sex $(p=0.526$ and $\mathrm{p}=0.396$, respectively). Percentage of retirees were respectively $71.0 \%$ and $52.8 \%$ in group 1 and group 2, and there was no

Table 1. Comparison of neck disability index and age on the groups

\begin{tabular}{|c|c|c|c|c|c|c|}
\hline & \multicolumn{2}{|c|}{ Group $1(n=31)$} & \multicolumn{2}{|c|}{ Group $2(\mathrm{n}=36)$} & \multirow[b]{2}{*}{$\mathrm{Z} / \mathrm{T}$ value } & \multirow[b]{2}{*}{$p$} \\
\hline & Mean rank & Mean \pm SD & Mean rank & Mean \pm SD & & \\
\hline $\begin{array}{l}\text { Neck disability index } \\
\text { Age }\end{array}$ & 41.00 & $55.7 \pm 11.5$ & 27.97 & $53.5 \pm 17.1$ & $\begin{array}{c}-2.734 \\
0.638\end{array}$ & $\begin{array}{l}0.006^{*} \\
0.526^{* *}\end{array}$ \\
\hline
\end{tabular}




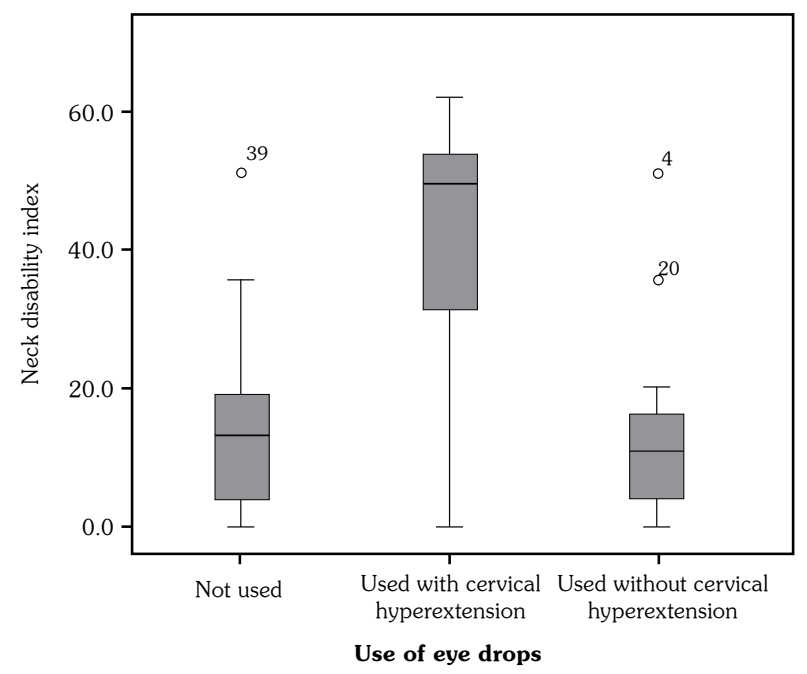

Figure 1. Figure demonstrating the effect of eye drop usage on neck disability index with different cervical positions.

statistically significant difference between the groups $(p=0.128)$ (Table 1$)$.

Use of eye drop and method of application generated a strong difference in the NDI of patients, and the NDI of patients was found to be higher when the eye drop was instilled in the cervical hyperextension position $(p<0.001)$ (Figure 1).

The NDI was found to be correlated with the age of patient, period of eye drop usage, number of drops instilled at a time and daily repetition number of the eye drops. All of these correlations were found to be statistically significant (Table 2).

\section{DISCUSSION}

Neck pain is still one of the most important health problems especially in industrialized countries. Together with limitations in daily life, neck pain also causes labor force loss making it a great socioeconomic problem. ${ }^{13,14}$
Many risk factors accompany the development of neck pain. Female sex, former neck injury and psychosocial problems are encountered as the most frequent risk factors. ${ }^{15,16}$ Furthermore, it is known that related risk factors such as repetitive work, constrained neck and head posture, repetitive neck movements, forceful arm movements and static postures involving neck or shoulder muscles, work-related risk factors such as inadequate job satisfaction and high job demands are among the risk factors which increase neck pain. , $2,17-19^{-}$

Different body postures and their effects on the flexor and extensor muscle groups have been evaluated by using electromyography, and it has been observed that long-term inappropriate posture had an influence on the development of neck pain by causing unbalanced and repetitive contraction of these muscle groups. ${ }^{20}$ Some authors have demonstrated a strong relationship between posture and neck pain, and they have emphasized the importance of habitual changes in the prevention and treatment of this discomfort. ${ }^{21-24}$

The NDI was found to be significantly related to neck pain and has been adapted for various cultures; and according to studies that have been performed for confirmation of its validity and reliability, a consensus has been reached about its properties in determining neck pain and disability. ${ }^{25-28}$

In this study, the effect of different neck postures during eye drop instillation on neck health was investigated and inappropriate posture of the cervical vertebrae in individuals using eye drops for the treatment of glaucoma was found to negatively affect neck health. To the best of our knowledge, there is no study that evaluates the relationship between neck problems and eye drop usage.

Table 2. The factors influencing on the neck disability index

Number of eye drop for each Frequency of application of Duration of eye drop use application/per a day eye drop/per a day

\begin{tabular}{|c|c|c|c|c|}
\hline \multicolumn{5}{|c|}{ Neck disability index } \\
\hline Rho & 0.286 & 0.362 & 0.348 & 0.426 \\
\hline$P$ value & 0.019 & 0.003 & 0.004 & $<0.001$ \\
\hline
\end{tabular}


Repetitive inappropriate neck posture can occur together with neck extension in individuals with chronic eye drop usage, for the management of glaucoma. The frequent determination of neck disability in patients who instill eye drop particularly in the extension position of the neck may explain the impact of neck posture on the development of neck pain. While neck disability is encountered mostly in individuals who instill eye drops by placing their neck in the hyperextension position, it was seen infrequently in individuals who have not had a history of eye drop usage and also in those who have used eye drops in other positions apart from the hyperextension position. According to development of neck disability, no statistically significant differences were reported between patients who have not had a history of long-standing eye drop usage and patients who have had long-standing eye drop usage in positions other than the hyperextension position of the neck. This result may be important in supporting our hypothesis (Figure 1). In addition to these results, it was found that there could be a positive correlation between the development of neck disability and the frequency of eye drop usage per a day, the number of eye drop for each application per a day, and the period of eye drop usage.

Additionally, dry eye syndrome is an important condition that is frequently encountered primarily or secondarily to rheumatic diseases. ${ }^{29}$ Artificial tear drops are occasionally used for its treatment. Neck pain can also arise from chronic instillation of eye drops in a wrong position; yet chronic eye drop administration can be necessary for some eye diseases frequently seen in the course of rheumatic diseases. ${ }^{30}$ Therefore, this problem is not only associated with primary eye diseases, but can also be related to rheumatic diseases. These patients should be instructed by clinicians about the correct position of the neck, such as avoiding the hyperextension position while instilling eye drops.

There are some limitations of the study. Firstly, neck pain is a multifactorial pathology and although there are similar demographic properties of the patients, it may not be possible to exclude all factors other than eye drop usage for standardization. Secondly, the study has been designed as a cross-sectional study. NDI scores before the start of eye drop treatment and the scores after one year of the treatment for the same patient in a prospective manner could perhaps be a better study design.

In conclusion, despite the limitations, these preliminary findings can suggest that patients who have to use eye drops for a long time may suffer from chronic neck pain due to an inappropriate postural changes. Neck disability may be avoided by only changing postural habits while instilling eye drops. Placing the neck by avoiding the hyperextension position while using eye drops significantly decreases neck disability and neck pain. Patients who are to use eye drops for a long time should be informed about postural disorders that may lead to neck pain. However, in order to confirm findings of the current study, additional studies with quantitative and objective tests are required.

\section{Declaration of conflicting interests}

The authors declared no conflicts of interest with respect to the authorship and/or publication of this article.

\section{Funding}

This work was founded by the Turkish League Against Rheumatism.

\section{REFERENCES}

1. Ariëns GA, van Mechelen W, Bongers PM, Bouter LM, van der Wal G. Physical risk factors for neck pain. Scand J Work Environ Health 2000;26:7-19.

2. Ariëns GA, Bongers PM, Douwes M, Miedema MC, Hoogendoorn WE, van der Wal G, et al. Are neck flexion, neck rotation, and sitting at work risk factors for neck pain? Results of a prospective cohort study. Occup Environ Med 2001;58:200-7.

3. Edmondston SJ, Sharp M, Symes A, Alhabib N, Allison GT. Changes in mechanical load and extensor muscle activity in the cervico-thoracic spine induced by sitting posture modification. Ergonomics 2011;54:179-86.

4. Szeto GP, Straker L, Raine S. A field comparison of neck and shoulder postures in symptomatic and asymptomatic office workers. Appl Ergon 2002;33:75-84.

5. Eltayeb S, Staal JB, Hassan A, de Bie RA. Work related risk factors for neck, shoulder and arms complaints: a cohort study among Dutch computer office workers. J Occup Rehabil 2009;19:315-22. 
6. Leske MC, Heijl A, Hyman L, Bengtsson B, Komaroff E. Factors for progression and glaucoma treatment: the Early Manifest Glaucoma Trial. Curr Opin Ophthalmol 2004;15:102-6.

7. Heijl A, Peters D, Leske MC, Bengtsson B. Effects of argon laser trabeculoplasty in the Early Manifest Glaucoma Trial. Am J Ophthalmol 2011;152:842-8.

8. Gedde SJ, Singh K, Schiffman JC, Feuer WJ. The Tube Versus Trabeculectomy Study: interpretation of results and application to clinical practice. Curr Opin Ophthalmol 2012;23:118-26.

9. Katz G, Dubiner H, Samples J, Vold S, Sall K. Three-month randomized trial of fixed-combination brinzolamide, $1 \%$, and brimonidine, $0.2 \%$. JAMA Ophthalmol 2013;131:724-30.

10. Thieme $H$, van der Velden KK. Preservatives from the perspective of glaucoma surgery. Ophthalmologe 2012;109:1073-6.

11. Bicer A, Yazici A, Camdeviren H, Erdogan C. Assessment of pain and disability in patients with chronic neck pain: reliability and construct validity of the Turkish version of the neck pain and disability scale. Disabil Rehabil 2004;26:959-62.

12. Vernon H, Mior S. The Neck Disability Index: a study of reliability and validity. J Manipulative Physiol Ther 1991;14:409-15.

13. Cagnie B, Danneels L, Van Tiggelen D, De Loose V, Cambier D. Individual and work related risk factors for neck pain among office workers: a cross sectional study. Eur Spine J 2007;16:679-86.

14. Picavet HS, Schouten JS. Musculoskeletal pain in the Netherlands: prevalences, consequences and risk groups, the DMC(3)-study. Pain 2003;102:167-78.

15. Andersen JH, Kaergaard A, Mikkelsen S, Jensen UF, Frost $\mathrm{P}$, Bonde JP, et al. Risk factors in the onset of neck/shoulder pain in a prospective study of workers in industrial and service companies. Occup Environ Med 2003;60:649-54.

16. Croft PR, Lewis M, Papageorgiou AC, Thomas E, Jayson MI, Macfarlane GJ, et al. Risk factors for neck pain: a longitudinal study in the general population. Pain 2001;93:317-25.

17. Caneiro JP, O'Sullivan P, Burnett A, Barach A, O'Neil $\mathrm{D}$, Tveit $\mathrm{O}$, et al. The influence of different sitting postures on head/neck posture and muscle activity. Man Ther 2010;15:54-60.

18. Elliott JM, O'Leary SP, Cagnie B, Durbridge G, Danneels L, Jull G. Craniocervical orientation affects muscle activation when exercising the cervical extensors in healthy subjects. Arch Phys Med Rehabil 2010;91:1418-22.
19. Leroyer A, Edmé JL, Vaxevanoglou X, Buisset C, Laurent P, Desobry P, et al. Neck, shoulder, and hand and wrist pain among administrative employees: relation to work-time organization and psychosocial factors at work. J Occup Environ Med 2006;48:32633.

20. Falla D, Jull G, Hodges PW. Feedforward activity of the cervical flexor muscles during voluntary arm movements is delayed in chronic neck pain. Exp Brain Res 2004;157:43-8.

21. Falla D, O'Leary S, Fagan A, Jull G. Recruitment of the deep cervical flexor muscles during a posturalcorrection exercise performed in sitting. Man Ther 2007;12:139-43.

22. Jull GA, O'Leary SP, Falla DL. Clinical assessment of the deep cervical flexor muscles: the craniocervical flexion test. J Manipulative Physiol Ther 2008;31:52533.

23. Watson AW, Mac Donncha C. A reliable technique for the assessment of posture: assessment criteria for aspects of posture. J Sports Med Phys Fitness 2000;40:260-70.

24. Brink Y, Louw QA. A systematic review of the relationship between sitting and upper quadrant musculoskeletal pain in children and adolescents. Man Ther 2013;18:281-8.

25. Vos CJ, Verhagen AP, Koes BW. Reliability and responsiveness of the Dutch version of the Neck Disability Index in patients with acute neck pain in general practice. Eur Spine J 2006;15:1729-36.

26. Ackelman BH, Lindgren U. Validity and reliability of a modified version of the neck disability index. J Rehabil Med 2002;34:284-7.

27. Salo P, Ylinen J, Kautiainen H, Arkela-Kautiainen M, Häkkinen A. Reliability and validity of the finnish version of the neck disability index and the modified neck pain and disability scale. Spine (Phila $\mathrm{Pa}$ 1976) 2010;35:552-6.

28. Aslan E, Karaduman A, Yakut Y, Aras B, Simsek IE, Yagl $\mathrm{N}$. The cultural adaptation, reliability and validity of neck disability index in patients with neck pain: a Turkish version study. Spine (Phila Pa 1976) 2008;33:E362-5.

29. Wolfe F, Michaud K. Prevalence, risk, and risk factors for oral and ocular dryness with particular emphasis on rheumatoid arthritis. J Rheumatol 2008;35:1023-30.

30. Cohen S, Martin A, Sall K. Evaluation of clinical outcomes in patients with dry eye disease using lubricant eye drops containing polyethylene glycol or carboxymethylcellulose. Clin Ophthalmol 2014;8:157-64. 